\title{
A laboratory Incubator equipped with facilities to automatically simulate natural irradiance
}

\author{
Ludwig ALETSEE ${ }^{1}$ \& Marcus E. M. BAUMANN ${ }^{2}$
}

${ }^{1}$ Abteilung für Systematik und Geobotanik der Rheinisch-Westfälischen Technischen Hochschule Aachen

(Worringer Weg 1, 5100 Aachen, F.R.G.)

${ }^{2}$ Alfred-Wegener-Institute for Polar and Marine Research

Am Handelshafen 12

D-2850 Bremerhaven, F.R.G.

- Abstract: An incubator is described which automatically simulates fluctuations of natural irradiance by coupling a photocell to a lightbank in the ship's laboratory. Design details are given.

- Descriptors: Primary production, Irradiance, Laboratory equipment, Automated recording, Simulators.

- Descritores: Produção primária, Irradiação, Equipamento de laboratório, Registro automatizado, Simuladores.

\section{Introduction}

Although the "in situ" exposure is the most direct method of measuring primary production, this is often not practical at sea. The necessary long periods in a stationary position are often not feasible because of technical and financial reasons (Gargas, 1975), together with problems such as rough seas or drifting incubation. In view of this, attempts have been made by many workers to measure primary production by simulating the "in situ" conditions in deck incubators. In these methods samples are exposed to sunlight in chambers which are cooled by flowing surface seawater. Each sample is placed under a neutral density screen to mimic the light conditions from which the samples were taken (Gargas, 1975).

One disadvantage of such an incubator is that in polar regions low air temperatures and winds may cause freezing of the incubator's brine (the difference between these two temperatures may be more than $15^{\circ} \mathrm{C}$ ). The cooling down of the deck incubator caused by this difference may be more than $4^{\circ} \mathrm{C}$ compared to surface water temperature. Howeve under bright sunshine the cooling by surface water may be insufficient. Such temperature variations may significantly bias rate measurements. However, taking into account that the temperature problem might be resolved by the use of an efficient cooling together with a reheating possibility, another important disadvantage of a deck incubator remains unsolved: it cannot be installed on deck without being occasionally shadowed by the ship's superstructure so that the light may differ considerably from those of the "in situ" conditions. Therefore an incubator inside a ship's laboratory which can closely simulate the natural variations in irradiance as well as the surface water temperature is desirable. In this paper such an incubator is described. It has successfully been used for the purpose of estimating primary production during the Marginal Ice Zone Experiment 1984 (MIZEX) on board the FS "Polarstern", and on a second cruise to the Arctic in May 1985.

A further decisive advantage of this kind of incubator should be mentioned. Whit the help of a computer, suitably programmed, all natural daylight changes, which have been recorded during the expedition are stored on electronic data files which can be easily accessed later.

\section{Operation mode}

Light is monitored in the laboratory incubator using a photodiode. This is compared with the natural irradiance measured by a second photodiode above the crow's nest, automatically aligned by an electronic wiring with a time delay of $0.5 \mathrm{~s}$ (maximum). Photon flux densities ranging from $0.66 \mu \mathrm{mol}^{-2} \mathrm{~s}^{-1}$ up to $430 \mu \mathrm{mol}^{-2} \mathrm{~s}^{-1}$ can be measured using a $4 \pi$ quantummeter (Licor, Inc.), when white chamber walls are used. The spectral composition of the light in the respective depths from which the samples have 
been taken can be simulated by the use of special light tubes in addition to special filters. The desired temperature can be held constant between $-5^{\circ} \mathrm{C}$ and $+25^{\circ} \mathrm{C}\left( \pm 0.1^{\circ} \mathrm{C}\right)$ by means of two cooling units.

\section{Description}

Figure 1a, b, c show schematically the construction of the incubator from three sides. The incubator basin is divided into two halves by a crosswall made of PVC. These halves can be cooled separately. The pipes of the cooling unit occupy one third of the chamber. The remaining space is again divided into two parts by another PVC wall (Fig. 1c).

Each half of the incubator is provided with two pumps ( 2 and 3, see Fig. 1a, b) to guarantee a homogeneous circulation of brine. Pump 2 (Fig. 1b) ensures circulation between the tubes of the vaporizer; Pump 3 (Fig. 1a, b) draws the brine in from the bottom below the tubes and introduces it again by a branched pipe system into the chambers B1 and B2, respectively B3 and B4 (Fig. 1a). Small holes in the introductionary pipe system cause a water stream upwards which keeps the incubation bottles in motion so that sedimentation of the plankton is reduced to a minimum. Eight $100 \mathrm{ml}$ bottles can be simultaneously suspended on a rack and put into each chamber (B1 - B4). Light is supplied by ten cool white fluorescent tubes which are installed on the moveable chassis at each side of the incubator. Light control can be made either by hand or automatically.

Figure 2 shows the wiring diagram of the automatic portion of the light control. All electric appliances used are given. In Figure 3 the wiring-diagram to the fluorescent tubes and the wiring of the dimmer which is regulated by the automatic part of the light control is shown. Philips intensity gradiation fluorescent tubes (TL 45 RS) were used. Dimming does not influence the spectral composition of their light. Filters of any kind (glass or net) can be installed in front of the chamber B1 -B4 (see Fig. 1c 6) to obtain one most probable alignment to the spectral composition of the light below the surface and to simulate different light depths. The natural procession of the daylight is stored on a floppy disc during the measurement via computer by means of a special programm. During two expeditions into the Arctic (MIZEX, 1984 and ARK III/1, 1985) some comparative production measurements could be made. The results have shown that the described incubator is suitable for experimental work under simulated conditions.

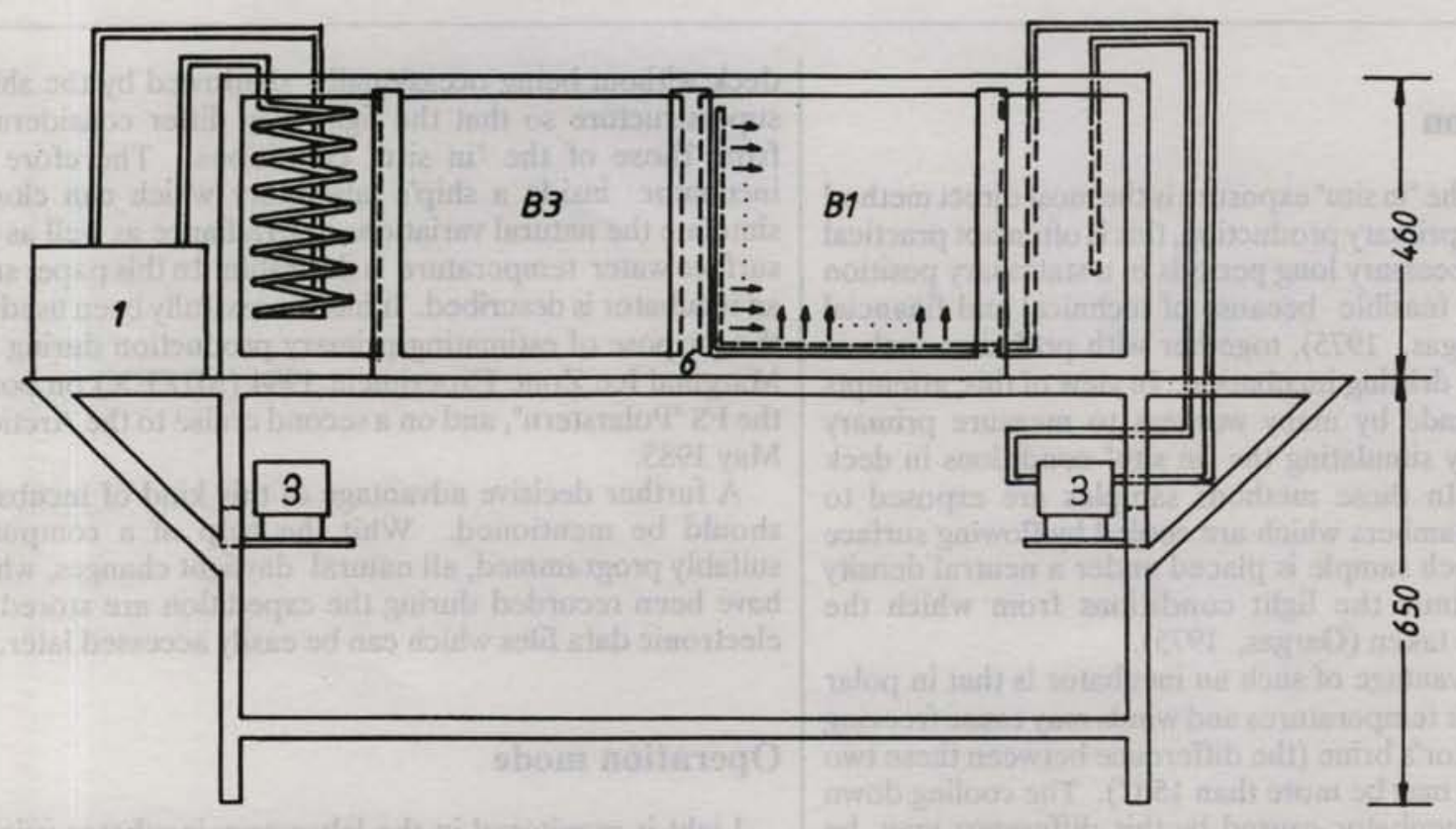

Fig. 1a. View from the front side on the incubator with cooling unit (1) and pump (3) (the pipe of the left pump and the right cooling unit are left out). B1 and B2 indicate two incubation chambers. The arrows show the water influx through the holes of the pipesystem (see text). Size figures are in $\mathrm{mm}$. 


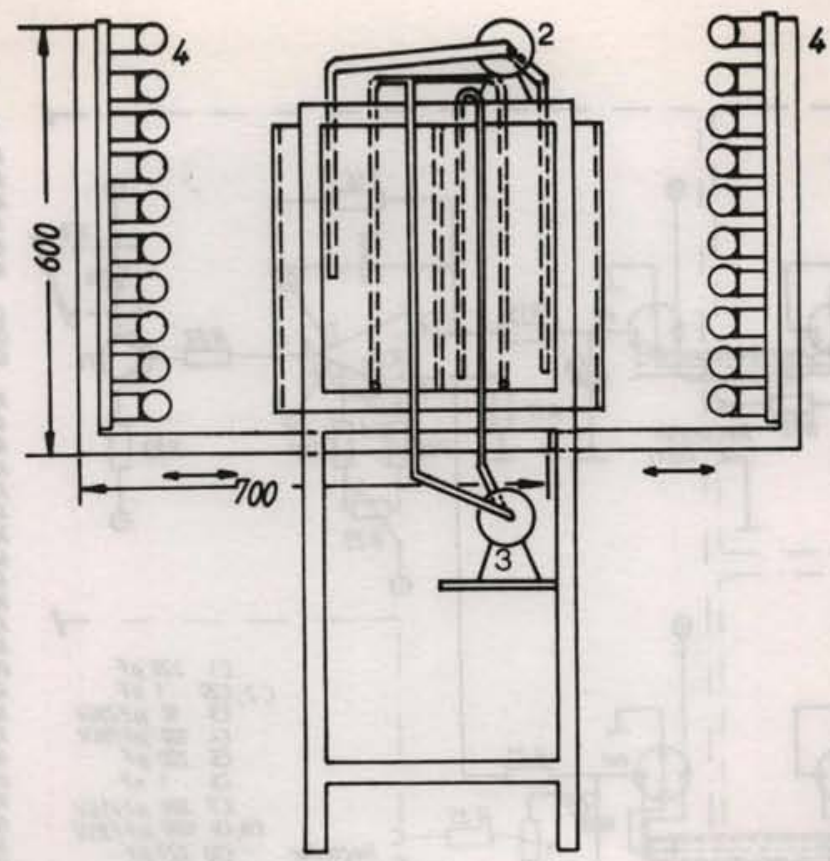

Fig. 1b. View from one side on incubator with pumps $(2,3)$ and lighting appliance (4). Size figures are in $\mathrm{mm}$.

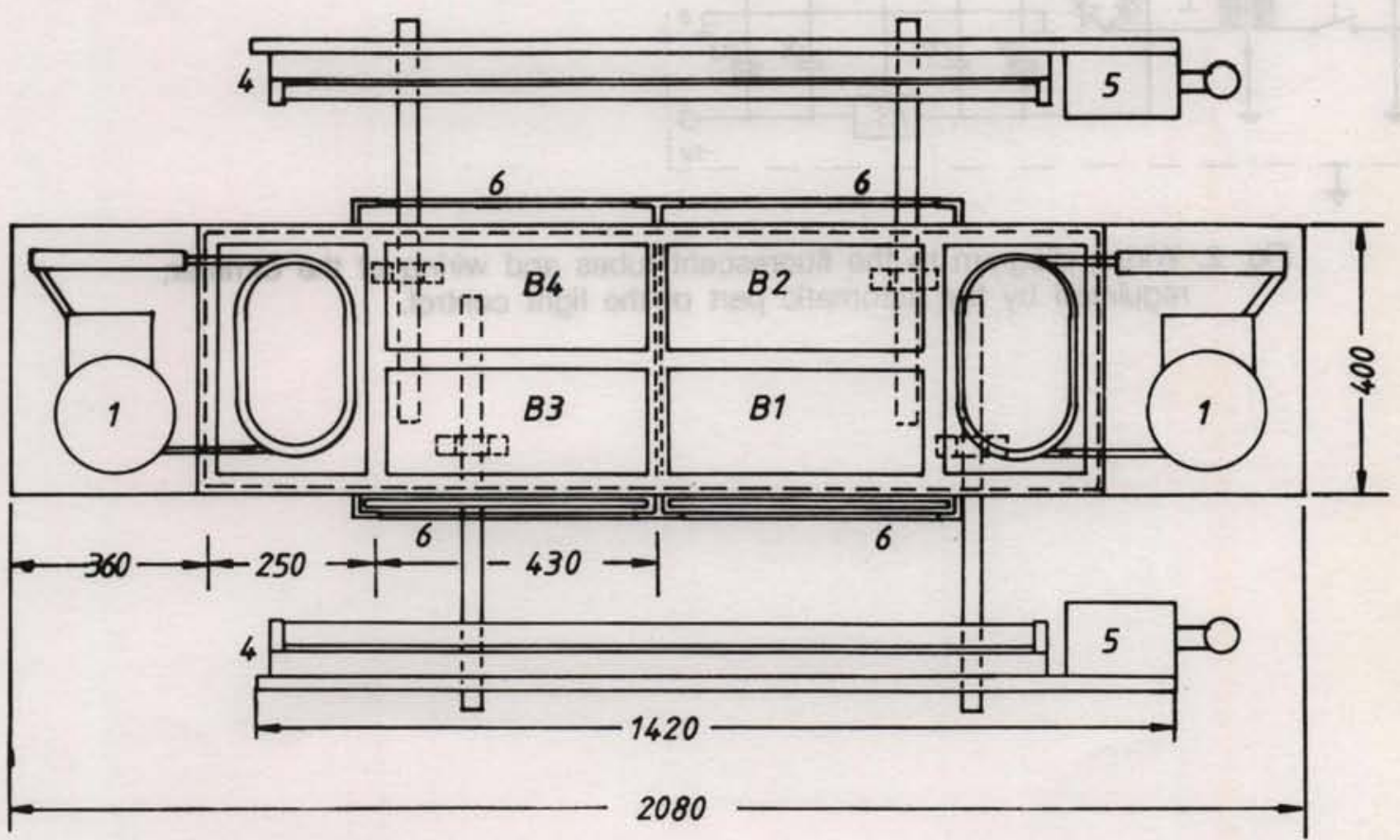

Fig. 1c. View from above on the incubator (pump 2 and 3 are left out) 1 cooling unit; 4 light supply, 5 electronic wiring, 6 filterracks with filters. B1, B2, B3 and B4 indicate the four incubation chambers. Size figures are in $\mathrm{mm}$. 


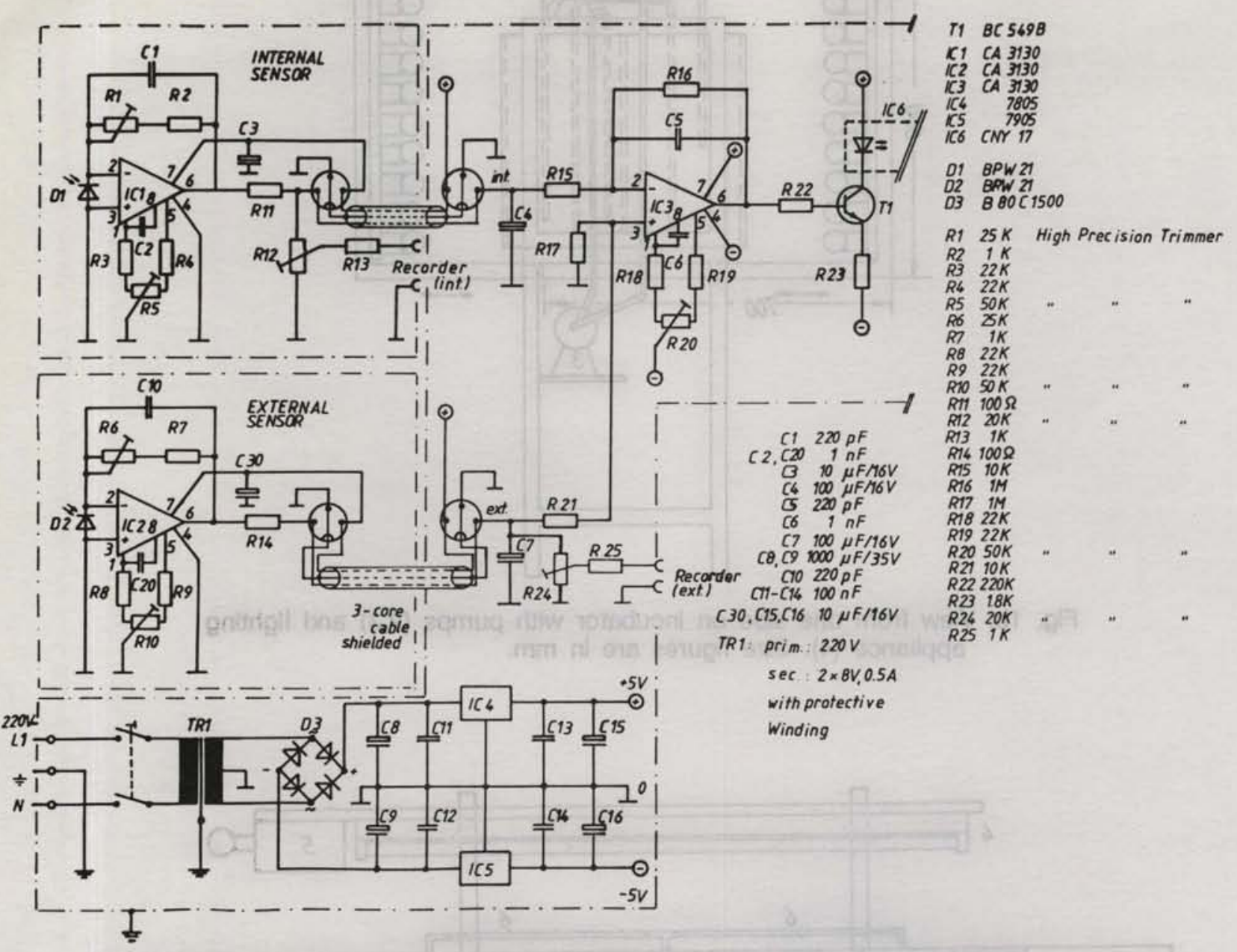

Fig. 2. Wiring diagram to the fluorescent tubes and wiring of the dimmer, regulated by the automatic part of the light control. 


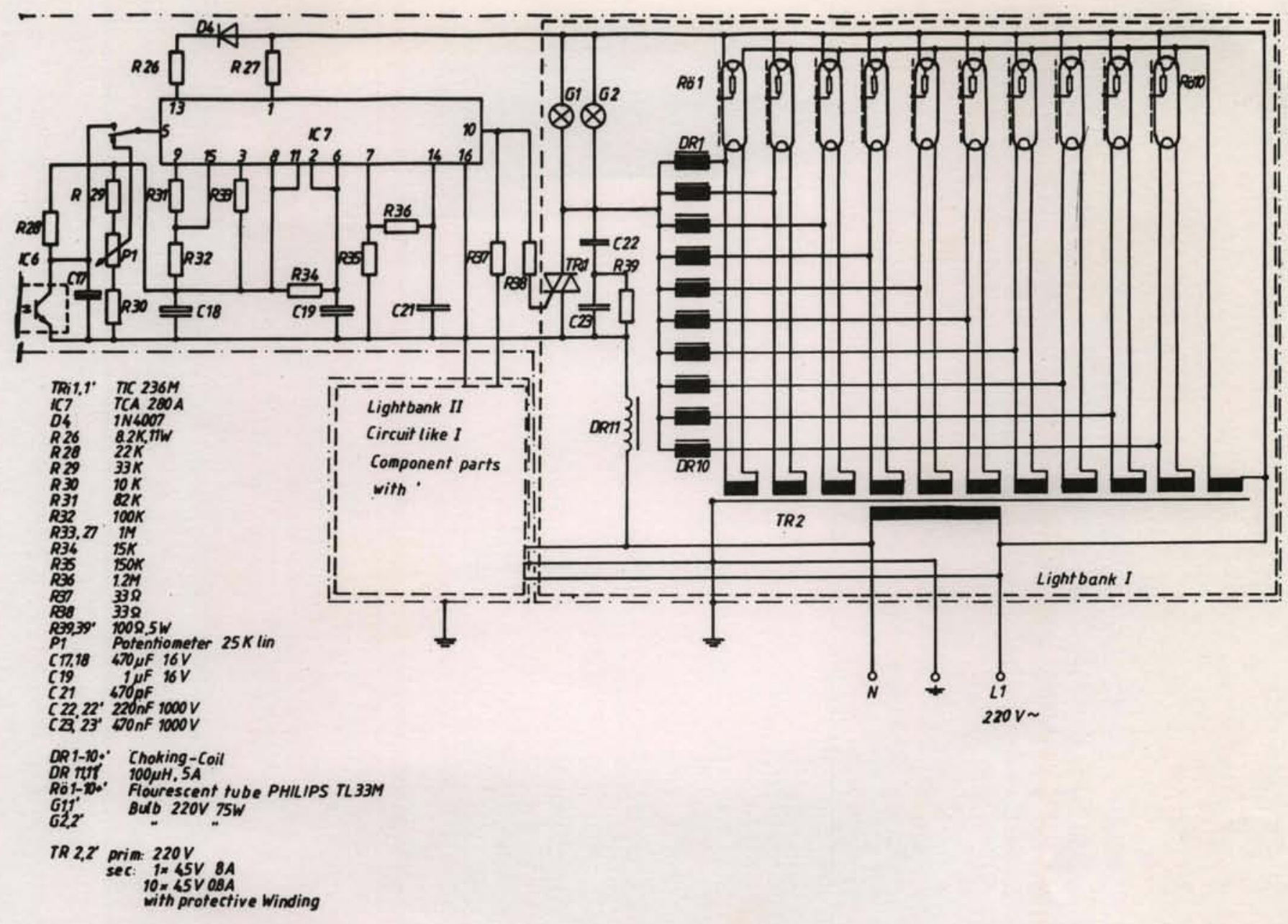

Fig. 3. Wiring diagram to the fluorescent tubes and wiring of the dimmer, regulated by the automatic part of the light control.

\section{Acknowledgements}

We are grateful to Jo Blatt who carried out and performed the electronic wiring and drew the figures. We gratefully announce the financial support by the Deutsche Forschungs Gemeinschaft (DFG), grant Al 45/5-1. We appreciate the critical comments by David Thomas. Further details especially concerning the recording of the data on electronic carriers by computer and the reproduction of the natural proceeding of the daylight may be obtained from the authors.

\section{Reference}

GARGAS, E. 1975. A manual for phytoplankton primary production studies in the Baltic. BMB publications No. 2, 88 .

(Manuscript received 31 July 1991, accepted 12 November 1991) 